\title{
Cloud Computing: A Paradigm Shift in the Way of Computing
}

\author{
Mohit Agarwal \\ Department of Physics \& Computer Science, Dayalbagh Educational Institute, Agra, India \\ Email: rs.mohitag@gmail.com \\ Dr. Gur Mauj Saran Srivastava \\ Associate Professor, Department of Physics \& Computer Science, Dayalbagh Educational Institute, Agra, India \\ Email: gurmaujsaran@gmail.com
}

Received: 16 October 2017; Accepted: 11 November 2017; Published: 08 December 2017

\begin{abstract}
Cloud computing has been emerging out as a new and evolving paradigm with tremendous momentum. It is one of the most acceptable information technology based service which drew the attention of the people not only from the academia, industry but also registered its popularity among the general people. Features like scalability, elasticity, less entry cost, easy to access and subscription and pay per use etc. compel the businesses and end users to migrate themselves from the traditional platform to the cloud based platform. With the wide acceptability of cloud computing based services in the society, people have various myths like some think it as a new name of internet, as it shares many features of the internet while others feel it as another name of existing technology like distributed system, grid computing, and parallel computing etc.. This paper will help in making people aware of this technology by highlighting the points of difference with the existing technology and focusing on the various advantages and area of application which presents the evidence of its popularity and continual growth. The work in the paper will end with the discussion on the status of various issues and shortcomings from which it is suffering along with the present and future scope in this popular area.
\end{abstract}

Index Terms-Cloud computing, Grid computing, Distributed computing, Utility computing, Virtual machines (VM's)

\section{INTRODUCTION}

Internet and the services which are based on it dominate the last two decades in information technology world. As the dependency of the human being on technology is increasing day by day, the demand of accessing the computing resources, storing and processing of the data at third party site round the clock was much needed. Cloud computing presents itself as the solution to the above demands by providing the computing facilities round the clock across the globe over the internet on the plug and pay basis as they are accessing the day to day life utilities like electricity, telephone or mobile services, gas etc. Cloud computing has changed the way of using the computing infrastructure as the resources are provided to the consumer and released by the consumer on the basis of their demands from the shared pool of resources [1]. This on-demand resource provisioning proves very economical to the consumer as they are supposed to pay only for the resources they have used and this feature allows the service provider to re-allocate the released resources [3]. Gartner (2013), in its report of the year 2013 on cloud computing anticipated the growth of $18.4 \%$ and $\$ 155$ billion markets of public cloud services for the year 2014.As Fig. 1 shows the overall market is supposed to grow from $\$ 93$ billion to $\$ 210$ billion in the period 2011 to 2017 [2].

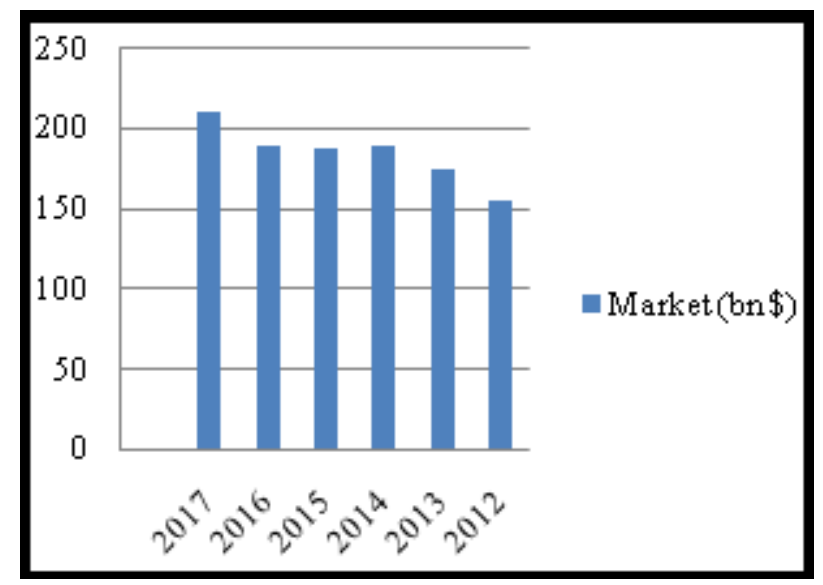

Fig.1. Gartner Market Forecast (billion \$).

The aim of this paper is to present the comprehensive overview of the cloud computing with the help of right description and discussion of all important related aspect of this technology. For the better understanding, this paper is divided into various sections which are as follows: Section 2 presents the overview of cloud computing which focuses on the various definitions of cloud computing from different - different perspective and also presents the architecture of cloud computing which enables the reader to understand the concept and 
its workflow along with this this section also contains the essential characteristics, services, and various deployment models along with the important actors from the cloud computing point of view. Section 3 will focus on the evolution of cloud computing technology. Section 4 emphasize on comparison different technology which looks similar to cloud. Section 5 will present the SWOT analysis while section 6 which will focus on the application areas of cloud. Section 7 will present the present and future status of cloud computing followed by conclusion in Section 8.

\section{Cloud Computing Overview}

This section helps us to understand the overview of Cloud computing which includes its definition from different perspective, architecture of cloud computing, essential characteristics which are responsible this kind of growth in such a short duration, various service models which are going to be followed by the description of deployment models and their suitability, and lastly various actors also bring into the picture who have a influential role in this paradigm.

\section{A. Definition}

As cloud computing is still in the infancy and with the increase in popularity and acceptability of cloud computing, many researchers came forward with their own definition as no one agreed-upon one common definition. The reason might be that the cloud computing is the integration of many computing technologies with aim of providing fast computation facilities to the users over the internet. Many researchers came forward with their definition of cloud computing [13 - 16] and we are presenting most acceptable definition:

National Institute of Science and Technology (NIST) came forward with widely accepted definition which used to define the cloud computing with all necessary features [5] as follows: "Cloud Computing as a model for enabling convenient, on-demand network access to a shared pool of configurable computing resource (e.g. servers, networks, storage, applications and services) that can be rapidly provisioned and released with minimal management effort or service provider interaction".

Based on our survey and perception towards the cloud computing, we provide the definition of cloud computing which stresses to include the important features: " a cloud is nothing but a huge pool of easily accessible and usable computing resources (like networking components, storage units, computing units and others) which must be available to the intended users round the clock and across the globe over the internet on pay-per-use basis. The computing must provide the resources scalability feature so that they must be reconfigurable on the basis of load to support the concept of resource usage optimization".

The definition of cloud model proposed by the NIST also emphasizes that a complete model must (a) five essential characteristics (b) three service models and (c) four deployment models.

\section{B. Essential Characteristics}

Characteristics, as shown in Fig. 2 which help the cloud computing in gaining the popularity and acceptability over other computing models, are as follows:

\section{On-demand self-service}

This feature enables the cloud service user (CSU) to request and manage the computing capabilities like server time, network storage etc. without any human intervention from cloud service provider (CSP) as and when needed.

\section{Broad networks access}

This characteristic of cloud model ensures the accessibility of the services, applications, and data over the network round the clock and across the globe to CSU through standard mechanism and protocols. The feature also ensures that the services should be accessible through heterogeneous thin and thick clients like mobile phones, tablets, laptops, PDA's etc.

\section{Resource Pooling}

The computing resources like processing units, storage or memory units, network bandwidth, virtual network and virtual machine etc. should be maintained as a pool of resources.

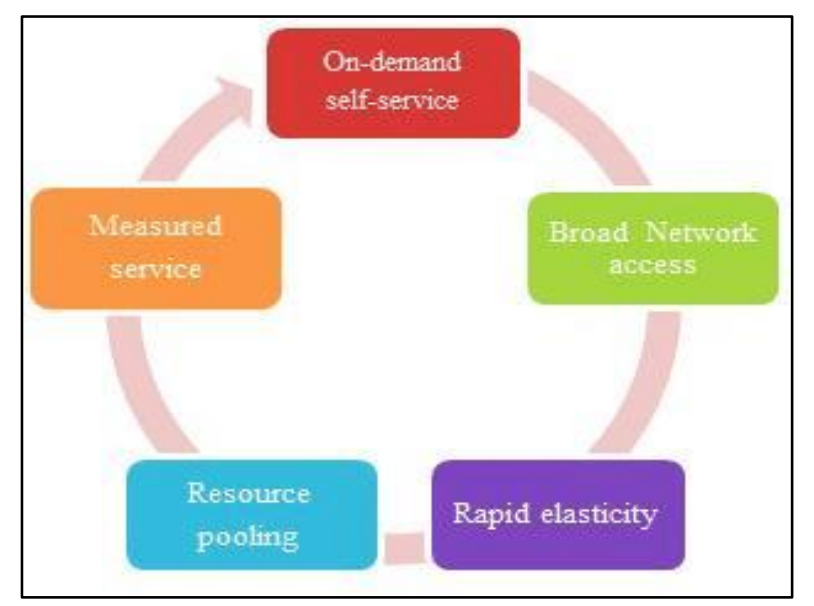

Fig.2. Characteristics of Cloud Computing

This feature ensures the allocation of the resources to the user and re-allocation of the same resources to another user as they get free from the current user to support a multi-tenant environment as per the user demand.

\section{Rapid Elasticity}

The resources should be maintained in such a way that they must be rapidly and elastically scaled in or scaled out as per the CSU demand. The user must have the impression that they have the accessibility to unlimited resources which can be purchased as and when needed.

\section{Measured Services}

As the above features of cloud model enable the user to access and elastically scaled in and scaled out the 
Table 1. Actors in cloud computing

\begin{tabular}{|c|c|}
\hline Actors & Definition \\
\hline $\begin{array}{l}\text { Cloud } \quad \text { Service } \\
\text { Provider }(C S P)\end{array}$ & $\begin{array}{l}\text { Responsible for making the services available to the intended users. Five major areas } \\
\text { activities are as follow service deployment, service orchestration, service management, } \\
\text { security, and privacy. }\end{array}$ \\
\hline $\begin{array}{l}\text { Cloud Service User } \\
(C S U)\end{array}$ & $\begin{array}{l}\text { They are the major stakeholder in cloud computing services. They used to enroll } \\
\text { themselves for the services of the cloud service provider. Service level agreements } \\
(S L A \text { 's }) \text { are needed a sign, to check the cloud service provider performance. }\end{array}$ \\
\hline Cloud Auditor & $\begin{array}{l}\text { An independent authority that looks after the quality of services provided by the CSP to } \\
\text { CSU's. }\end{array}$ \\
\hline Cloud Broker & $\begin{array}{l}\text { An entity that used to manages the usage, performance and negotiates with the CSP and } \\
\text { CSU. His service can be categorized as service intermediation, service arbitrage, and } \\
\text { service Aggregation. }\end{array}$ \\
\hline Cloud Carrier & $\begin{array}{l}\text { They used to provide connectivity for the transportation of services from the CSP to } \\
\text { CSU. }\end{array}$ \\
\hline
\end{tabular}

resources dynamically on their demand basis [41-42]. The measured service characteristic of cloud model is responsible for the metering out of the resources i.e. when and where what number of resources were underutilization and report the same to the user and service provider.

\section{Service Models}

The services offered by the cloud computing is broadly categorized into three service models as shown in Fig. 3 [38].

\section{Software as a Service (SaaS)}

This service model allows the consumer to avail the cloud services or applications which are managed and controlled by the CSP, over the internet. The thin client interface like web browsers is used to access the cloud applications. This model enables the various users at the same time to access the services [36]. Users are not permitted to install their software on the cloud infrastructure. Salesforce.com and Google are leader in this category. Emails and social networking account are some of the examples of such services.

\section{Platform as a Service (PaaS)}

This service model allows the cloud users to deploy their applications on the cloud infrastructure using the programming languages and development tools provided by the cloud service provider. The user has no control or managing rights over the underlying cloud infrastructure i.e. storage, operating systems, networks or servers but only have the control over the deployed applications [43]. Google app engine is one of the examples.

\section{Infrastructure as a Service (IaaS)}

In this service model, consumers are provided with the storage, networks, processing units and other required fundamental computing resources so that they will deploy and run their software including the operating system.
The main control over the infrastructure lies with the CSP but the user has control over the operating system, deployed applications, storage and limited control over networking components like hosts firewalls.

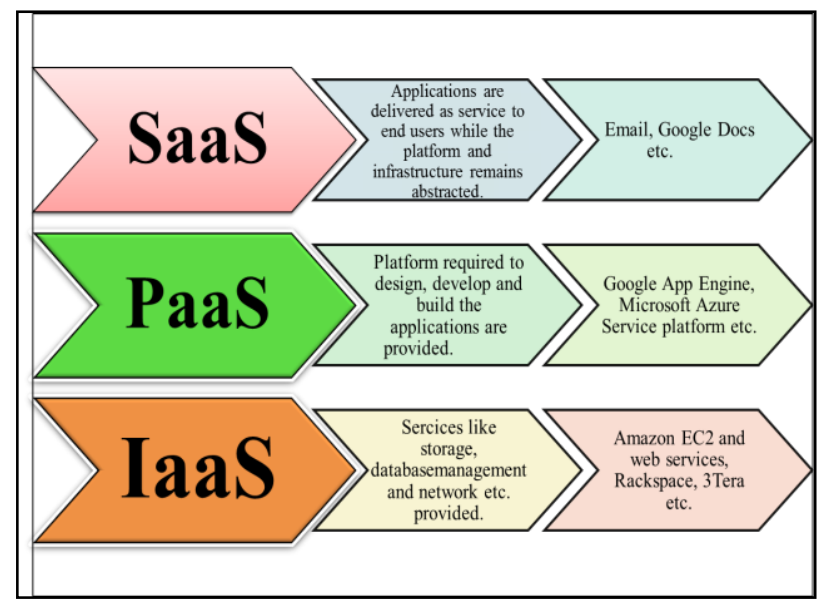

Fig.3. Cloud Computing Service Models.

\section{Cloud Deployment Models}

Cloud based computing models can be deployed primarily in four ways on the basis of the requirement of the users as shown in Fig. 4.

\section{Public Cloud}

Such clouds are open to all general public and organization but are owned and managed by the cloud service provider (CSP). The consumers are supposed to pay on the basis of their usage. Such clouds are located at the CSP site.

\section{Private Cloud}

Clouds which are developed for a specific organization for their personal work are termed as a private cloud. Such cloud may or may not be managed by an organization for which they are developed or may be 
managed by a third party. They may exist in the premises or outside the premises also.

\section{Community Cloud}

Such clouds are developed for a group of users or organizations which share some goal of interest like mission, policy or security consideration etc. They may be managed by an organization of a community or by the third party and may be located in premise or off-premise.

\section{Hybrid Cloud}

Any combination of two or more above clouds i.e. public, private or community is termed as hybrid cloud. The participating clouds retain their unique entity but are bound together with the standard protocols.

\section{E. Actors in Cloud Computing}

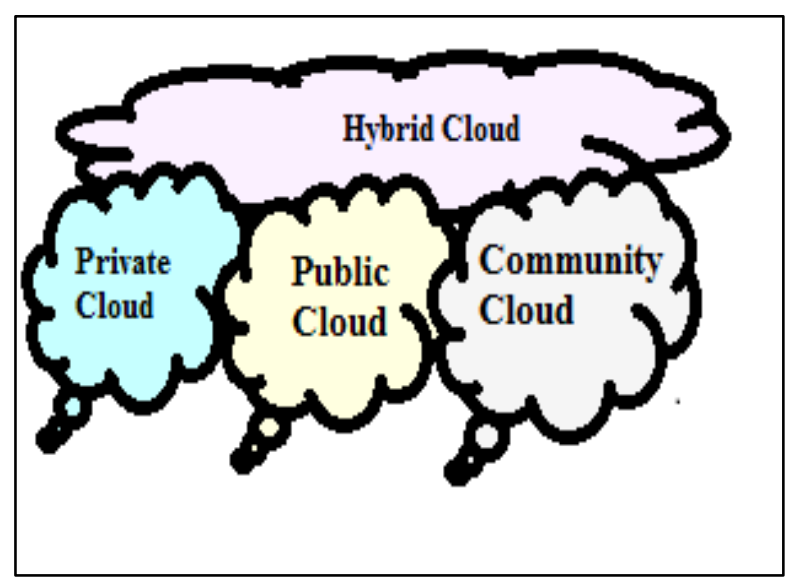

Fig.4. Cloud Computing Deployment Models.

\section{Cloud Computing TIMELINE}

Since the 1960s, a lot of research work has been done by the research community for the development of a new computing model termed as Cloud Computing. The motive was to provide the computing facilities to the users over the internet like users availing the day to day utilities such as electricity, water, telephone, and gas etc. In 1950's the term "time - sharing" was coined which is now considered as one of the underlying technology of cloud computing. At that time, there was the huge demand in both academia as well as in large organizations to access the information or data on separate terminals. As mainframe system was too costly, in order to save money they decide to go for the CPU time shared system. In 1969, J.C.R. Licklider introduced the concept of "intergalactic computer network". As a result, Licklider developed the ARPANET (Advanced Research Projects Agency Network) with the hope that one day anybody can access the data from anywhere over the network. It was 1990's which brings a revolution in the field of information technology with the introduction of "Internet" which makes the data available to anybody from anywhere using www or .com facility. In 1997, Prof. Ramnath Chellapa was the first who used the term "Cloud Computing". The first major breakthrough in the field of cloud computing came in 1999 in the form of Salesforce.com, the first publicly available cloud service to its users through the internet. This enables the users to use the application software which is not installed on their local machines.

The next major development in the history of cloud computing came in 1992 with the introduction of Amazon Web Services (AWS). This service was provided with computation, storage along with the human intelligence to a certain extent to its users. Later on, in 2006 Amazon Elastic Cloud (EC2) was introduced as a commercial web service which enables the small organization or individuals to rent computers to run their own applications to carry out their personal or business operations. Salesforce.com in 2007 expanded itself in the form Force.com with the aim to provide a developer based platform which enables the organization to build and run their application software and websites using the cloud. In 2008, the market saw the entry of big and prominent player like Google and Microsoft with their products Google App Engine which provide the very economical storage and computation facility and by 2009 ; it also enables the users to store their documents in the cloud while Microsoft introduces Windows Azure to provide the cloud based services. Apple introduced iCloud to enables its users to sync music, apps, photos and documents along with the string of devices.

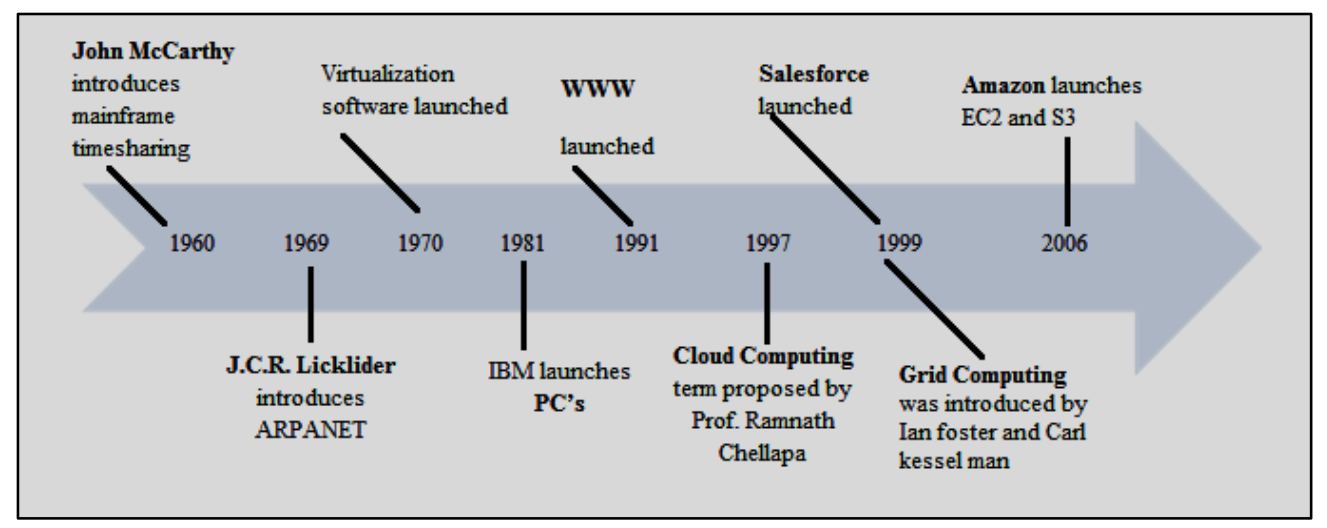

Fig.5. Cloud Computing Timeline. 


\section{COMPARISON WITH EXISTING TECHNOLOGIES}

Cloud computing is very often used to compare with the following technologies and each of them share certain features with the cloud paradigm.

\section{A. Grid Computing}

Grid computing may be described as the distributed computing paradigm which coordinates the network resources to achieve the required computational objective. Scientific applications are one of the driving factors which led to the development of grid computing as they require intensive computing to achieve the goal. The grid size may vary from small network of computers within an organization to large collection of computing machine across many organizations. Buyya et al. [11] define a grid as a parallel and distributed system which enables selection; sharing and aggregation of geographically distributed independent computing resources dynamically depend on their capability, availability, cost, performance and user requirements. Large scale, heterogeneity, geographical distribution, resource coordination and resource sharing are some of the characteristics which make this model of computing so popular.

\section{B. Utility Computing}

With the development of technology, the demand of computing as a utility was increasing among the various sections of the information technology users. Utility computing as the name suggests enables the users to use the computing resources like electricity, water, telephone and energy on the pay per use basis instead of flat fee charging. The major benefit of this computing model is better economics.

Table 2. Comparison of Grid, Utility and Cloud computing

\begin{tabular}{|c|c|c|c|}
\hline Features & Grid Computing & Utility Computing & Cloud Computing \\
\hline Virtualization & Beginning & Less & Essential \\
\hline Resource Management & Centralized & Centralized & Centralized/Distributed \\
\hline Scalability degree & Low & Normal & High \\
\hline Transparency & Very Low & High & High, optional \\
\hline Ownership & Multiple & Single & Single \\
\hline Operating System & Any standard & Linux using windows and Solaris & Hypervisor \\
\hline Control & Centralized & Centralized & Decentralized \\
\hline $\begin{array}{l}\text { Standardization/ } \\
\text { Accessibility }\end{array}$ & Using grid middleware & On backup policy & Using standard web protocols \\
\hline Capability & High & Service based & On demand provision \\
\hline Security & Key pair based authentication & Login on password basis & $\begin{array}{c}\text { Individual VM is provisioned for each } \\
\text { application }\end{array}$ \\
\hline Examples & Amazon 08 & SETI & Amazon EC2 \\
\hline Future model & Cloud computing & Cloud and grid computing & Next generation computing \\
\hline
\end{tabular}

\section{SWOT ANALYSIS}

\section{A. Strength}

This section will focus on the unexplored benefits of cloud computing. Cloud computing offers the ability to scale up at a very short notice at the point of peak demand. Cloud computing also offers users the time distributed computing resources. Cloud computing also leads to a reduction in infrastructure, maintenance and up gradation cost along with the energy saving. Economies of scale of the data center can result in 5 to 7 times reduction in total computing cost [9]. Cloud computing also enables the organization to have the better control i.e. where, when and how employees can access the computing resources of the company with the help of web based interface. Example Amazon management console is used to control the Amazon web services (AWS).

\section{B. Weakness}

There are lots of issues which need to be addressed for the deeper penetration of cloud based services among the organization. Like, organizations have no control over the location of storage of data in the cloud. As a result service providers are constantly working on this issue.
AWS launches the Amazon Virtual Private Cloud which enables the users to connect them to the isolated AWS system through Virtual Private Network (VPN).

\section{Opportunities}

Cloud Computing offers many opportunities to its users and we are going discuss some important ones. First, government agencies especially in growing or developing nations like India and others may use this as an instrument to reach its citizens to provide public welfare schemes such as e- classrooms, health awareness programs, maintaining and keeping track of public distribution systems etc. as cloud computing based applications do not require any major investments for setting the infrastructure, in training the peoples and others in comparison to the orthodox information technology based applications. Second, cloud computing also helps the organization in reducing the operating cost as well as carbon emission.

\section{Threats}

As more and more organization are looking to migrate themselves to the cloud based services which in turn may provide them much time to focus on their core business but other IT departments view it as the biggest threats in 
terms of data security, company's standard and even as a threat to their job security. One of the biggest factors that can hamper the growth of cloud services is the regulatory norms at local, national as well as at international front which can range from data security, privacy, and location requirements.

\section{ApPlication AREA of Cloud COMPUting}

Since its inception, Cloud Computing find its application across almost all the areas what we can imagine, some of them are discussed below:

\section{A. Cloud computing in agriculture sector}

Earlier, Agriculture was used to be considered as the commercial activity which involves less exposure to technology in terms of labor, machinery, storage etc. but with the globalization of the world's economy, this field also hints that with application or adoption of current technology in this area may result in unforeseen development. Especially, adoption of the Information technology may attract and boost the people involved in this industry as such adoption helps them in a better understanding of the soil behavior, cultivation on land, filling of taxes and storage and management related issue of their crops. The main advantage of deploying the IT based infrastructure in agriculture related activities is in weather forecasting, prediction of the rain in current and coming years and also detecting other activities which may affect the crop and agriculture yields. All this involves the huge collection of data and its processing which may result in huge investments in infrastructure and training of the people. To avoid such investments, the government is deploying more and more cloud based applications in most of the countries like Japan [7], India and also in developed nations like the USA and Europe.

\section{B. Cloud computing in education and research}

As more and more organization are migrating themselves from traditional computing to cloud based computing as it enables any users to access the resources simultaneously. Nowadays, research laboratory and educational institutes also require some platform which can support features like (a) multiple programming models, (b) allows researchers and educationalist to develop their own applications as per demand using the extensible framework and (c) multiple cloud (public, private or hybrid) deployments. An example of such product is Aneka [11] which is used by educational and research institute like MSRIT- Bangalore, NIT Karnataka and Centre for Development of Advanced Computing (CDAC) Hyderabad to set up their cloud labs.

\section{Cloud computing in medical and healthcare sector}

In comparison to the other industries, Healthcare industry desperately needs the Information Technology based applications because most of their tests are paper based and test results need to be communicated between different actors like patients, physician and other experts to their consideration. So adoption of the Information technology with cloud computing at the test center helps this industry a lot. Cloud computing enables the healthcare industry i.e. hospitals, research facilities, practitioners etc. to avail latest computing resources and infrastructure at a very nominal rate without any upfront investments. It also takes care of the following key requirements of the industry [38] which are not addressed by traditional IT support:

- By providing the computing resources for huge data sets of health records, test reports etc. on demand basis.

- Providing large storage capacity to store computed results of above data sets.

- Sharing and timely access to crucial health data.

\section{Cloud computing in engineering and manufacturing}

Cloud computing also finds its application in the manufacturing and engineering domain as well. As this industry spread from automotive to aerospace market, so they have to face challenges like optimization of their IT spending which include huge infrastructure cost in setting the environment for designing of new products. So cloud enables them to focus on their core business instead of on IT infrastructure.

\section{CURRENT Status AND Future}

Several reports have shown the remarkable growth in the adoption or shifting towards the cloud computing. Gartner [4] in his report of 2016 presents the notable change in IT spending as present in Table 4 i.e. shifting from traditional IT based system to cloud based system.

Table 4. IT spending prediction

\begin{tabular}{|c|c|l|l|c|}
\hline $\begin{array}{c}\text { Legacy } \\
\text { System }\end{array}$ & $\begin{array}{l}\text { Cloud } \\
\text { System }\end{array}$ & $\begin{array}{l}\text { Market } \\
\text { Size 2016 }\end{array}$ & $\begin{array}{l}\text { Shift to } \\
\text { Cloud } \\
\mathbf{2 0 1 6}\end{array}$ & $\begin{array}{l}\text { Cloud } \\
\text { shift } \\
\text { Rate by } \\
\mathbf{2 0 2 0}\end{array}$ \\
\hline BPO & PaaS & $\$ 119 \mathrm{bn}$ & $\$ 42 \mathrm{bn}$ & $43 \%$ \\
\hline AS & SaaS & $\$ 144 \mathrm{bn}$ & $\$ 36 \mathrm{bn}$ & $37 \%$ \\
\hline AIS & PaaS & $\$ 177 \mathrm{bn}$ & $\$ 11 \mathrm{bn}$ & $10 \%$ \\
\hline SI & IaaS & $\$ 294 \mathrm{bn}$ & $\$ 22 \mathrm{bn}$ & $17 \%$ \\
\hline $\begin{array}{l}\text { BPO }=\text { Business Process Outsourcing; AS = Application } \\
\text { Software; AIS }=\text { Application Infrastructure Software; SI = } \\
\text { System Infrastructure }\end{array}$
\end{tabular}

As we can clearly make out from the table 4, the total shift in the market from traditional to the cloud may reach to $\$ 111$ billion which can reach up to $\$ 216$ billion by 2020. Business organizations are using various cloud models to meet their needs like public $(60 \%)$, private (62\%) and hybrid (26\%) as the report of Forbes [12]. A Recent report by Forbes (2016) on cloud computing which is based on a survey done by IDG's as a part of which 925 respondents were interviewed. In this paper, we also consider the report published by RightScale 
(2016) in which 1060 technical profession took the part in the survey conducted by them. The sample of the respondent is presented in below Fig. 6 .

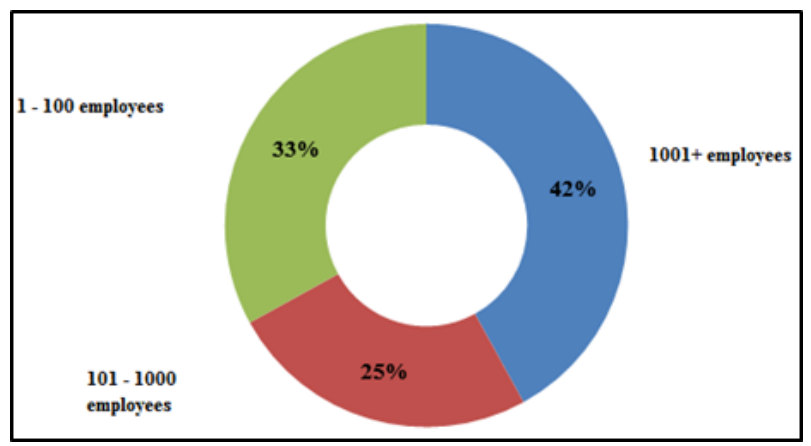

Fig.6. Respondents by Company Size.

In this section, we are presenting the recent trends in cloud computing:

\section{A. Adoption of cloud based infrastructure}

The survey conducted by Forbes as shown in Fig. 7 presents that, how cloud computing based infrastructure became an integral part of the organizations. About $70 \%$ organizations having at least one application on the cloud while $75 \%$ organizations having 1000 or more employee having the same. One of the important outcomes regarding the adoption of cloud infrastructure is the $90 \%$ organizations either already using it or going to shift over this in time spam of $12-36$ months.

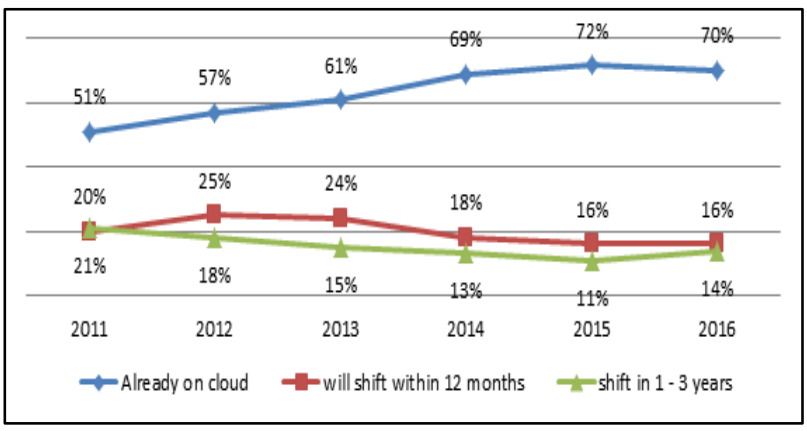

Fig.7. Organizations planning to use cloud infrastructure

\section{B. Applications and their migration to the cloud}

The Forbes survey also shows the adoption status or plan to migrate in future to the cloud for the various applications like Email/ messaging, collaboration, data storage/ data management, human resource, business/ data analytics and much more. The outcome suggests that a large number of organizations are looking to migrate to cloud based application in coming years for data storage and business analytics area as shown in Fig. 8.

\section{Cloud based benefits}

One of the major findings of the RightScale 2016 survey is the shift in major benefits provided by the cloud computing in comparison to findings of previous surveys. Two benefits which report major growth includes faster access to infrastructure rise to $\mathbf{6 2 \%}$ in 2016 which was $\mathbf{5 7 \%}$ in 2015 and faster time - to - market reaches 52\% in 2016 in comparison to $48 \%$ in 2015. Apart from these benefits, the other ones are greater scalability (58\%), Higher availability (52\%) and much more as shown in the Fig. 9 below.

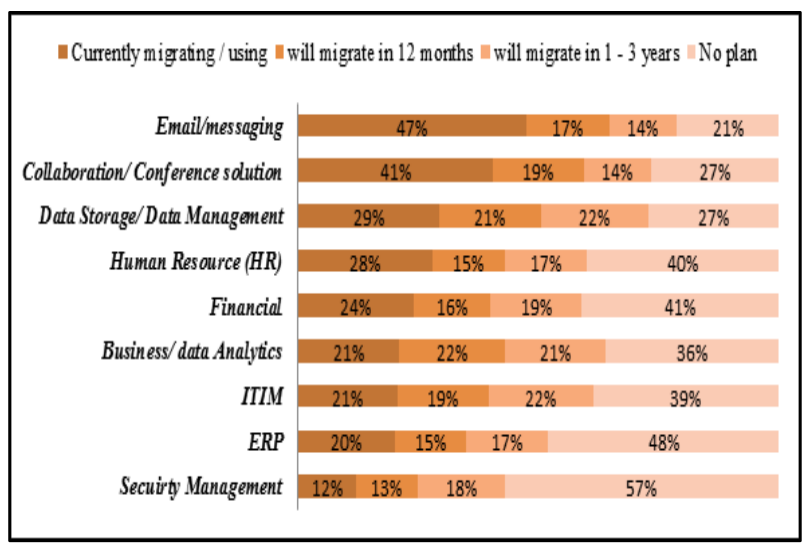

Fig.8. Migration Plan to Cloud

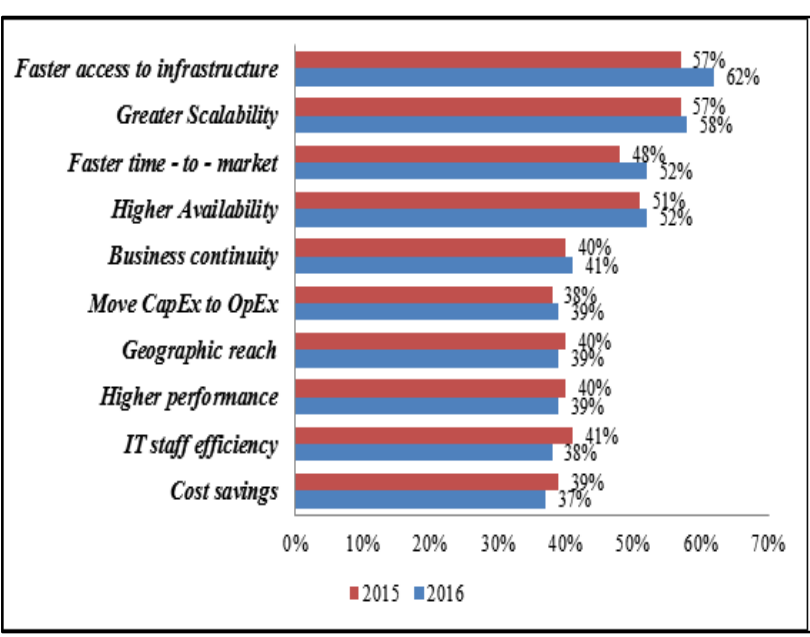

Fig.9. Change in Benefits (2016 VS 2015).

\section{Lack of resources/ expertise replaces security as a challenge}

Like other emerging technology, cloud computing also brings some challenges along with the number of benefits as discussed earlier in this paper. With the advancement in technology, we saw a good downfall in challenges. As per RightScale survey 2013 [RightScale, 2013], security always remain as the main challenge in cloud computing [9] but in present scenario Lack of resource/ expertise [8] emerges out as an top most challenge which attracts the attention of the industry which rise from $27 \%$ in 2015 to $32 \%$ in 2016. The status of challenges is also presented below which came out as the part of the survey. 


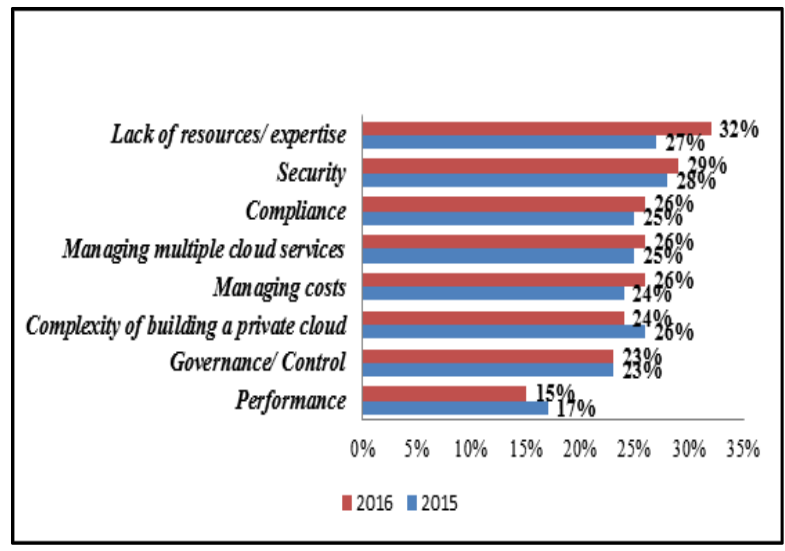

Fig.10. Challenges with adoption of cloud (2016 VS 2015).

\section{CHALLENGES}

Cloud Computing is still in infancy and with more and more acceptability and adaptability many new challenges keep on emerging. We are going to discuss such some issues in this section.

\section{A. Security}

Security is emerging out as one of the biggest challenges which is the hampering the adoption rate of the Cloud Computing model among the organization [17]. The reason is that organization is quite reluctant to share their confidential documents and business related data with the cloud service provider [21] because unlike in traditional IT based infrastructure where the control lies with the administrator, in cloud computing model the service provider is dependent on the infrastructure provider for the hardware resources. The service providers also do not have the administrative control over infrastructure and services [27]. Over this in cloud computing model, the numbers of the user have the accessibility to the same set of the hardware resources due to the underlying technologies like virtualization and multitenancy also added the weight to the doubt. Lots of researchers put their views on the security issue in cloud computing as reported in the literature [25, 32 and 35] some of them relate those with accountability, integrity, confidentiality [30] and author also suggested the defense strategies for these. Many more solutions also been reported in the literature to counter one or more security issues some of the are: Lombardi et al. [39] proposes Advanced cloud security system (ACPS) for the more security of the cloud resources in cloud model while author in [23] proposed a security tool named CyberGuarder which used to provide security to virtual network.

\section{B. Energy Management}

Development of energy efficient cloud system is also one of the major challenges in adoption of cloud computing. This is because data centers needed energy for to perform basic operations, cooling, power supply etc. and this energy cost used to contribute a very sizable portion in the total operating cost of cloud [18]. As per Amazon survey, 53\% of their total cost was consumed by the servers over the period 3 years of amortization while power usage and cooling requirements used to contribute $42 \%$ to their total budget for 15 years of amortization period [19]. The growth in the adoption of cloud computing based technology is also increasing the concern like growth in electricity demand and also emission of carbon from such huge data centers. For the year 2010, electricity demand from the global data centers was about $1.3 \%$ of the total of world electricity usage. According to a report from Gartner, McKinsey and Stanford University, the carbon emission from the worldwide data centers will grow by about $400 \%$ in the year 2020 in comparison to the year 2007 as shown in Fig. 11. As per the reports, during the year 2006 data centers in the United States consumed $1.5 \%$ of the total energy produced [20].

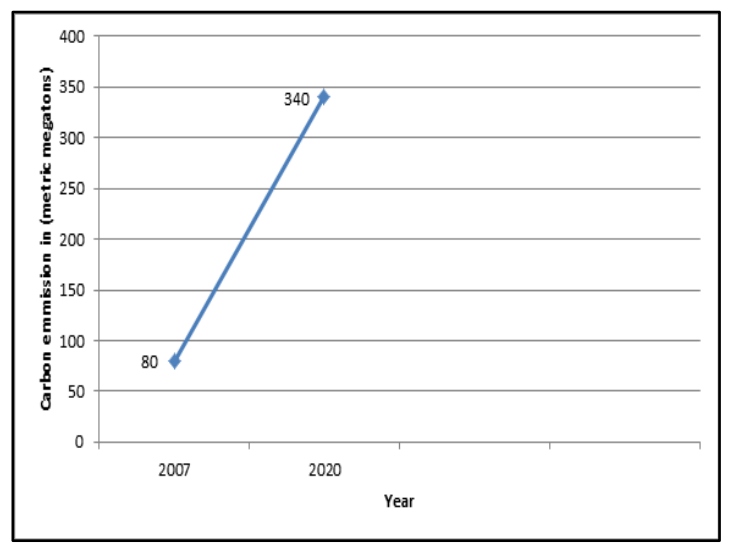

Fig.11. Carbon emission from the datacenters across the globe

The major reason responsible for data centers energy inefficiency is the wastage of power even when computing resources run at low utilization. For example, even at server load of $10-12 \%$, the power consumption by data centers will around $50 \%$ of that of peak load [22]. The researcher tries to sort out the energy management issue and they put forward the following solutions as per the literature: a). increasing the resource utilization, b). the introduction of energy aware resource allocation strategy for DC's management, c). switching to permanent and efficient infrastructure to avoid resource replacement and, d). avoid self- management of the DC's. Therefore, to make cloud computing model more and more robust and favorable among the organization so that they can migrate themselves from traditional IT based model to it. It is necessary to reduce both the energy dissipation and power consumption [40].

\section{Virtual machine migration}

Virtualization technique proves itself as the important enabling technology of the cloud computing paradigm as it helps in allocation of resources as well as energy management in data centers but it also has some limitations as it involves the process of virtual machine migration.VM migration used to burden the network and greatly affects network efficiency due to transfer data 
from one host to another host which used to create a huge amount of traffic in the data centers [33]. Live migration of VM involves copying and transfer of VM memory image from one host to another and consume huge network bandwidth to achieve the same. This huge data transfer over the network may put a challenge before the SLA's condition, high throughput and a minimum end to end delay.

\section{Data Storage}

Distributed data storage mechanism is adopted by the cloud computing based system in order to ensure highly reliable and economic computing service. Google file system (GFS) and Hadoop distributed file system (HDFS) are an example of the distributed data storage system.

\section{E. Service Level Agreement (SLA)}

Service level agreement may be defined as a formal document of negotiation between the CSP and users of the cloud services which aims to provide the quality and guaranteed QoS. It used to have the following points [24]:

- Identification and definition of the user requirements or needs.

- Provision of a prototype for a better understanding of user requirements.

- Mitigation of the complex issues.

- Encouragement of the communication in case of any conflicts, and

- Removal of any hypothetic expectations.

As per the literature $[25,29,42]$ suggests, the objective of signing the SLA between the CSP and the user is to select the best available CSP [37] on the basis of their declaration in the agreement, to control the overprovisioning which might affect the profitability of the service provider. The author in [31], presents the model based on virtual SLA to ensure the quality of QoS by applying them to the delegating tasks. The author in [29] put forward the model which is based on Weighted Round Robin and FIFO algorithms for the scheduling of data to ensure guaranteed QoS. SLA's may sometimes raise the implementation problems as different types of cloud services (SaaS, IaaS, and PaaS) require different different SLA's definitions.

\section{F. Availability and performance}

As per the IDC's survey, availability and performance are some of the important issues in cloud computing model. Every user has lots of expectation in terms of the performance and availability of the resources and services when they used to move their business to the cloud based service model. For the same, SAL's used to sign between the CSP and users to maintain the level of services. Performance is the measurement of the capabilities of the cloud system to perform the tasks. Factors like low bandwidth, improper memory management; CPU speed etc. may affect the cloud performance drastically. Availability in cloud computing which is somehow related to the system performance may be defined as the probability of getting the resource or service whenever they are demanded by the intended users with in the estimated time. Besides of the fact that the CSP deploys advanced technology for maintaining the quality of service, there might be the situation of denial of service, slow down in performance, outages problem and other related issues. Poor performance and no - availability of the concerned service may lead to the loss of the customers, reduction in revenue, end of the services and much more [26, 28]. Therefore, performance and availability should be addressed properly in order to provide quality services to the user which led to the growth of the business of the CSP [34].

\section{CONCLUSION}

Through this paper, we tried to present an overview or big picture of cloud computing paradigm. First, cloud computing is defined from different perspectives which also includes underlying architecture followed by essential characteristics, service models, deployment models along with the various participants or actors in the field of cloud computing. Second, a timeline of cloud computing is presented which shows how cloud computing covers its journey since the introduction of a mainframe computer to its birth in 2007. Third, comparison of the cloud computing is shown with similar kinds of existing technologies like grid computing and others which clearly shows how cloud computing has an extra edge over the other existing technologies.

Furthermore, present and the future scenario are presented with the help of the various surveys that are recently conducted by the leaders in the industry like Gartner, Forbes, and RightScale which help the reader to understand the penetration of cloud in the organizations, benefits level and the existing barriers which must be addressed properly. Finally, to ensure the long term success of cloud computing, this paper also covers the various challenges like; lack of resources/ expertise, security, compliance and much more that need proper attention to make its adoption much smoother.

This paper presents the broad overview of the cloud computing in very simple and effective manner so that the readers can easily understand the underlying concept and also paved the path for the future research in the area.

\section{ACKNOWLEDGMENT}

Authors would like to thanks the editor -in-chief for the support and all anonymous reviewers for the valuable comments to improve this paper.

\section{REFERENCES}

[1] K. Alhamazani, R. Ranjan, K. Mitra, F. Rabhi, P. P. Jayaraman, S. U. Khan, A. Guabtni, and V. Bhatnagar, "An overview of the commercial cloud monitoring tools: research dimensions, design issues, and state-of-the-art," Computing, vol. 97, no. 4, pp. 357-377, Apr. 2014. https://doi.org/10.1007/s00607-014-0398-5 
[2] K. Bilal, S. U. R. Malik, S. U. Khan, and A. Y. Zomaya, "Trends and challenges in cloud datacenters," IEEE Cloud Computing, vol. 1, no. 1, pp. 10-20, May 2014. https://doi.org/10.1109/mcc.2014.26

[3] A. S. Prasad and S. Rao, "A Mechanism Design Approach to Resource Procurement in Cloud Computing," IEEE Transactions on Computers, vol. 63, no. 1, pp. 17-30, Jan. 2014. https://doi.org/10.1109/tc.2013.106

[4] Gartner (2016)[online] http://www.gartner.com/events/emea/itfinancialprocureme ntassetmanagement. (Accessed 08 February 2017).

[5] P. M. Mell and T. Grance, "The NIST definition of cloud computing," 2011. https://doi.org/10.6028/nist.sp.800-145

[6] M. Armbrust, A. Fox, R. Griffith, A. Joseph, R. Katz, A. Konwinski, G. Lee, D. Patterson, A. Rabkin, I. Stoica, and M. Zaharia, Above the clouds: A berkeley view of cloud computing, in Tech. Rep. UCB/EECS-2009-28, EECS Department, U.C. Berkeley, February 2009.

[7] M. Hori, E. Kawashima, T. Yamazaki, "Application of Cloud Computing to Agriculture and Prospects in Other Fields", FUJITSU Sci. Tech, vol. 46, no. 4, pp. 446-454, October 2010.

[8] RightScale (2016) state-of-the-cloud [online] https://www.rightscale.com/lp/state-of-the-cloud ( Accessed 08 February 2017)

[9] V. Sharma and G. M. S. Srivastava, "Evolution and present status of cloud computing: a comprehensive analysis," International Journal of Business Information Systems, vol. 22, no. 2, p. 123, 2016. https://doi.org/10.1504/ijbis.2016.076243

[10] Gartner, "Forecast Overview: Public Cloud Services, Worldwide," 2011-2016, 4Q12 Update, 2013

[11] R. Buyya, K. Sukumar, "Platforms for Building and Deploying Applications for Cloud Computing", CoRR'11, pp. 6-11, 2011.

[12] Forbes (2017) Analytics, DataStorage Will Lead Cloud Adoption In 2017 [online]http://www.forbes.com/sites/louiscolumbus/2016/ 11/20/analyticsdatastoragewillleadcloudadoptionin2017/\# 5206bfb41497. (Accessed 08 February 2017).

[13] M. Klems, J. Nimis, and S. Tai, "Do Clouds Compute? A Framework for Estimating the Value of Cloud Computing," Lecture Notes in Business Information Processing, pp. 110-123, 2009. https://doi.org/10.1007/978-3-642-01256-3_10

[14] A. Jasti, P. Shah, R. Nagaraj, and R. Pendse, "Security in multi-tenancy cloud," 44th Annual 2010 IEEE International Carnahan Conference on Security Technology, Oct. 2010. https://doi.org/10.1109/ccst.2010.5678682

[15] L. Wang, J. Tao, M. Kunze, A. C. Castellanos, D. Kramer, and W. Karl, "Scientific Cloud Computing: Early Definition and Experience," 2008 10th IEEE International Conference on High Performance Computing and Communications, Sep. 2008. https://doi.org/10.1109/hpcc.2008.38

[16] I. Foster, Y. Zhao, I. Raicu, and S. Lu, "Cloud Computing and Grid Computing 360-Degree Compared," 2008 Grid Computing Environments Workshop, Nov. 2008. https://doi.org/10.1109/gce.2008.4738445

[17] D. A. B. Fernandes, L. F. B. Soares, J. V. Gomes, M. M. Freire, and P. R. M. Inácio, "Security issues in cloud environments: a survey," International Journal of Information Security, vol. 13, no. 2, pp. 113-170, Sep. 2013. https://doi.org/10.1007/s10207-013-0208-7

[18] L. A. Barroso and U. Hölzle, "The Datacenter as a Computer: An Introduction to the Design of Warehouse-
Scale Machines," Synthesis Lectures on Computer Architecture, vol. 4, no. 1, pp. 1-108, Jan. 2009. https://doi.org/10.2200/s00193ed1v01y200905cac006

[19] J. Hamilton, "Cooperative expendable micro-slice servers (CEMS): Low cost low power servers for internet-scale services", Proc. 4th Biennial CIDR, 2009.

[20] B. Li, J. Li, J. Huai, T. Wo, Q. Li, and L. Zhong, "EnaCloud: An Energy-Saving Application Live Placement Approach for Cloud Computing Environments," 2009 IEEE International Conference on Cloud Computing, 2009. https://doi.org/10.1109/cloud.2009.72

[21] A. N. Khan, M. L. M. Kiah, M. Ali, S. A. Madani, A. ur R. Khan, and S. Shamshirband, "BSS: block-based sharing scheme for secure data storage services in mobile cloud environment," The Journal of Supercomputing, vol. 70, no. 2, pp. 946-976, Aug. 2014. https://doi.org/10.1007/s11227-014-1269-8

[22] S. Srikantaiah, A. Kansal, F. Zhao, "Energy aware consolidation for cloud computing", Proc. HotPowerWorkshop Power Aware Comput. Syst., 2008Dec.

[23] J. Li, B. Li, T. Wo, C. Hu, J. Huai, L. Liu, and K. P. Lam, "CyberGuarder: A virtualization security assurance architecture for green cloud computing," Future Generation Computer Systems, vol. 28, no. 2, pp. 379390 Feb.

2012. https://doi.org/10.1016/j.future.2011.04.012

[24] B. R. Kandukuri, R. P. V., and A. Rakshit, "Cloud Security Issues," 2009 IEEE International Conference on Services $\quad$ Computing, 2009. https://doi.org/10.1109/scc.2009.84

[25] A. Abbas and S. U. Khan, "A Review on the State-of-theArt Privacy-Preserving Approaches in the e-Health Clouds," IEEE Journal of Biomedical and Health Informatics, vol. 18, no. 4, pp. 1431-1441, Jul. 2014. https://doi.org/10.1109/jbhi.2014.2300846

[26] Y. Ghanam, J. Ferreira, and F. Maurer, "Emerging Issues \&amp; Challenges in Cloud Computing-A Hybrid Approach," Journal of Software Engineering and Applications, vol. 05, no. 11, pp. 923-937, 2012. https://doi.org/10.4236/jsea.2012.531107

[27] R. Latif, H. Abbas, S. Assar, and Q. Ali, "Cloud Computing Risk Assessment: A Systematic Literature Review," Future Information Technology, pp. 285-295, 2014. https://doi.org/10.1007/978-3-642-40861-8_42

[28] T. Dillon, C. Wu, and E. Chang, "Cloud Computing: Issues and Challenges," 2010 24th IEEE International Conference on Advanced Information Networking and Applications, 2010. https://doi.org/10.1109/aina.2010.187

[29] K. Boloor, R. Chirkova, Y. Viniotis, and T. Salo, "Dynamic Request Allocation and Scheduling for Context Aware Applications Subject to a Percentile Response Time SLA in a Distributed Cloud," 2010 IEEE Second International Conference on Cloud Computing Technology and Science, Nov. 2010. https://doi.org/10.1109/cloudcom.2010.96

[30] Z. Xiao, Y. Xiao, "Security and Privacy in Cloud Computing", IEEE Commun. Surveys \& Tutorials, vol. 15, $\begin{array}{llll}\text { no. } 2, & \text { pp. } & 843-859, & \end{array}$ https://doi.org/10.1109/surv.2012.060912.00182

[31] V. Nae, R. Prodan, A. Iosup, and T. Fahringer, "A new business model for massively multiplayer online games," Proceeding of the second joint WOSP/SIPEW international conference on Performance engineering ICPE '11, 2011. https://doi.org/10.1145/1958746.1958785

[32] S. Subashini and V. Kavitha, "A survey on security issues in service delivery models of cloud computing," Journal 
of Network and Computer Applications, vol. 34, no. 1, pp. 1-11, Jan. 2011. https://doi.org/10.1016/j.jnca.2010.07.006

[33] Voorsluys, J. Broberg, S. Venugopal, and R. Buyya, "Cost of Virtual Machine Live Migration in Clouds: A Performance Evaluation," Cloud Computing, pp. 254-265, 2009. https://doi.org/10.1007/978-3-642-10665-1_23

[34] Lepakshi Goud, "Achieving Availability Elasticity and Reliability of the Data Access in Cloud Computing", Int'l J. Advanced Eng. Sciences and Technologies, vol. 5, no. 2, pp. 150-155, 2011.

[35] J. Che, Y. Duan, T. Zhang, and J. Fan, "Study on the Security Models and Strategies of Cloud Computing," Procedia Engineering, vol. 23, pp. 586-593, 2011. https://doi.org/10.1016/j.proeng.2011.11.2551

[36] T. Diaby and B. B. Rad, "Cloud Computing: A review of the Concepts and Deployment Models," International Journal of Information Technology and Computer Science, vol. 9, no. 6, pp. 50-58, Jun. 2017. https://doi.org/10.5815/ijitcs.2017.06.07

[37] Q. Tao, H. Chang, Y. Yi, and C. Gu, "A trustworthy management approach for cloud services QoS data," 2010 International Conference on Machine Learning and Cybernetics, Jul. 2010. https://doi.org/10.1109/icmlc.2010.5580998

[38] A. K. Bardsiri and S. M. Hashemi, "QoS Metrics for Cloud Computing Services Evaluation," International Journal of Intelligent Systems and Applications, vol. 6, no. 12, pp. 27-33, 2014. https://doi.org/10.5815/ijisa.2014.12.04

[39] F. Lombardi and R. Di Pietro, "Secure virtualization for cloud computing," Journal of Network and Computer Applications, vol. 34, no. 4, pp. 1113-1122, Jul. 2011 https://doi.org/10.1016/j.jnca.2010.06.008

[40] A. Berl, E. Gelenbe, M. Di Girolamo, G. Giuliani, H. De Meer, M. Q. Dang, and K. Pentikousis, "Energy-Efficient Cloud Computing," The Computer Journal, vol. 53, no. 7, pp. 1045-1051, Aug. 2009. https://doi.org/10.1093/comjnl/bxp080

[41] M. Agarwal and G. M. S. Srivastava, "A genetic algorithm inspired task scheduling in cloud computing," 2016 International Conference on Computing, Communication and Automation (ICCCA), Apr. 2016. https://doi.org/10.1109/ccaa.2016.7813746
[42] M. Agarwal and G. M. S. Srivastava, "A Cuckoo Search Algorithm-Based Task Scheduling in Cloud Computing," Advances in Intelligent Systems and Computing, pp. 293299, Sep. 2017. https://doi.org/10.1007/978-981-10-37733_29

[43] P. S. Suryateja, "A Comparative Analysis of Cloud Simulators," International Journal of Modern Education and Computer Science, vol. 8, no. 4, pp. 64-71, Apr. 2016. https://doi.org/10.5815/ijmecs.2016.04.08

\section{Authors' Profiles}

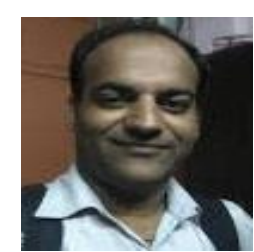

Mohit Agarwal was born in Agra, India. $\mathrm{He}$ received his B.Tech and M.Tech degree in Computer Science \& Engineering from the Uttar Pradesh Technical University and Amity University in 2007 and 2013 respectively. $\mathrm{He}$ is having around 2 years of working experience software developer and around 8 years as an Assistant Professor. Presently, he is pursuing Ph.D. in Computer Science from the Dayalbagh Educational Institute, Agra. He has published various papers in International refereed journals and conferences. His current research interest includes cloud computing, grid computing and distributed systems.

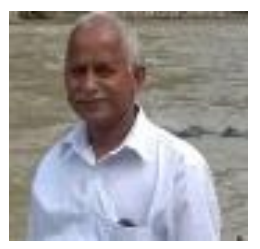

Dr. Gur Mauj Saran Srivastava was born in Agra, India. He received his B.Tech and Ph.D. degrees from ISM Dhanwad and Agra University, respectively. Currently, he is working as an Associate Professor in Department of Physics and Computer Science at Dayalbagh Educational Institute, Agra, India. He has published many papers in international journals and conferences. His current research interest includes Distributed System and Cloud computing.

How to cite this paper: Mohit Agarwal, Gur Mauj Saran Srivastava, "Cloud Computing: A Paradigm Shift in the Way of Computing", International Journal of Modern Education and Computer Science(IJMECS), Vol.9, No.12, pp. 38-48, 2017.DOI: $10.5815 /$ ijmecs.2017.12.05 